\title{
Device and Medication Preferences of Canadian Physicians for Emergent Endotracheal Intubation in Critically III Patients
}

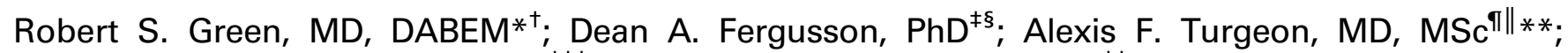
Lauralyn A. Mclntyre, MD, MHSc ${ }^{\ddagger \dagger}$; George J. Kovacs, MD, MHPE ${ }^{\ddagger \neq}$; Donald E. Griesdale, MD,

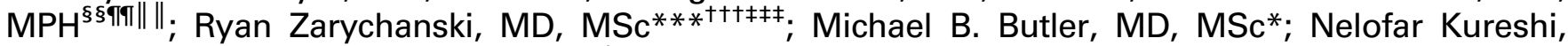
MBBS, $\mathrm{MHI}^{*}$; Mete Erdogan, $\mathrm{PhD}, \mathrm{MHI}^{\dagger}$; on behalf of the Canadian Critical Care Trials Group (CCCTG)

\section{ABSTRACT}

Objectives: Various medications and devices are available for facilitation of emergent endotracheal intubations (EETIs). The objective of this study was to survey which medications and devices are being utilized for intubation by Canadian physicians. Methods: A clinical scenario-based survey was developed to determine which medications physicians would administer to facilitate EETI, their first choice of intubation device, and backup strategy should their first choice fail. The survey was distributed to Canadian emergency medicine (EM) and intensive care unit (ICU) physicians using web-based and postal methods. Physicians were asked questions based on three scenarios (trauma; pneumonia; heart failure) and responded using a 5-point scale ranging from "always" to "never" to capture usual practice.

Results: The survey response rate was 50.2\% (882/1,758). Most physicians indicated a Macintosh blade with direct laryngoscopy would "always/often" be their first choice of intubation device in the three scenarios (mean $85 \%$ [79\%-89\%]) followed by video laryngoscopy (mean $37 \%$ [30\%-49\%]). The most common backup device chosen was an extraglottic device (mean 59\% [56\%-60\%]). The medications most physicians would "always/often" administer were fentanyl (mean 45\% [42\%-51\%]) and etomidate (mean $38 \%$ [25\%-50\%]). EM physicians were more likely than ICU physicians to paralyze patients for EETI (adjusted odds ratio 3.40; 95\% Cl 2.90-4.00).

Conclusions: Most EM and ICU physicians utilize direct laryngoscopy with a Macintosh blade as a primary device for EETI and an extraglottic device as a backup strategy. This survey highlights variation in Canadian practice patterns for some aspects of intubation in critically ill patients.

\section{RÉSUMÉ}

Objectifs: Différents dispositifs et différents médicaments s'offrent aux médecins pour faciliter l'intubation endotrachéale (IET) en extrême urgence. L'étude décrite ici visait à déterminer quels dispositifs et quels médicaments utilisent les médecins pour l'intubation au Canada.

Méthodes: Une enquête reposant sur des scénarios cliniques a été élaborée afin de déterminer quels médicaments utiliseraient les médecins pour faciliter I'IET en extrême urgence, quel serait leur premier choix de dispositif d'intubation et quelle serait leur solution de rechange en cas d'échec. Le questionnaire a été envoyé soit par voie électronique, soit par la poste aux urgentologues et aux intensivistes travaillant au Canada. Trois scénarios (trauma, pneumonie, insuffisance cardiaque) ont été soumis aux médecins, et ceux-ci devaient répondre aux questions à l'aide d'une échelle à 5 points variant de " Toujours " à " Jamais " pour indiquer leur pratique habituelle.

Résultats: Le taux de réponse à l'enquête a atteint 50,2 \% (882/ 1758). La plupart des médecins ont indiqué qu'une lame Macintosh sous laryngoscopie directe serait "Toujours " ou "Souvent " leur premier choix de dispositif d'intubation, et ce, dans les 3 scénarios (moyenne : $85 \%$ [79-89\%]), puis en vidéolaryngoscopie (moyenne : $37 \%$ [30-49\%]). L'instrument de rechange indiqué le plus souvent était un dispositif extraglottique (moyenne : 59 \% [56-60 \%]). Quant aux médicaments, les

From the *Department of Critical Care, Dalhousie University, Halifax, NS; †Trauma Nova Scotia, Halifax, NS; $¥$ Clinical Epidemiology Program, Ottawa Hospital Research Institute and the §Department of Medicine, Division of Clinical Epidemiology, University of Ottawa, Ottawa, ON; $\uparrow \mathrm{CHU}$ de Québec Research Center, Hôpital de I'Enfant-Jésus, Population Health and Optimal Health Practices Unit (Trauma-Emergency-Critical Care Medicine group) and the (Division of Critical Care Medicine, Department of Anesthesiology and Critical Care Medicine, Université Laval, Québec City, QC; ${ }^{* *} \mathrm{CHU}$ de Québec, Hôpital de l'Enfant-Jésus, Québec City, QC; ††Department of Medicine, Division of Critical Care Medicine, University of Ottawa, Ottawa, ON; ¥‡Department of Emergency Medicine, Dalhousie University, Halifax, NS; §§Department of Anesthesia, Pharmacology and Therapeutics and the Iा|Division of Critical Care Medicine, Department of Medicine, University of British Columbia, Vancouver, BC; $\||| C e n t r e$ for Clinical Epidemiology and Evaluation, Vancouver Coastal Health Research Institute, Vancouver, BC; ***Department of Internal Medicine, University of Manitoba, Winnipeg, MB; ††tDepartment of Haematology and Medical Oncology, CancerCare Manitoba, Winnipeg, MB; and the

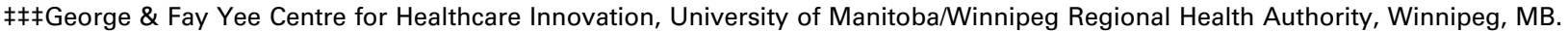

Correspondence to: Robert S. Green, Room 377 Bethune Building, 1276 South Park Street, Halifax, NS B3H 2Y9, Canada; Email: greenrs@dal.ca 
médecins administreraient "Toujours " ou "Souvent " le fentanyl (moyenne : $45 \%$ [42-51\%]) ou l'étomidate (moyenne : $38 \%$ [25-50\%]). Enfin, les urgentologues étaient plus nombreux à recourir à la paralysie des muscles pour les IET en extrême urgence que les intensivistes (risque relatif approché après rajustement : 3,40; IC à $95 \%: 2,90-4,00)$.

Conclusions: La plupart des urgentologues et des intensivistes ont recours à une lame Macintosh sous laryngoscopie directe comme premier dispositif d'IET en extrême urgence, et à un dispositif extraglottique comme solution de rechange. L'enquête fait ressortir des différences de pratique au Canada en ce qui concerne certains aspects de l'intubation chez les personnes gravement malades.

Keywords: intubation, device, medication

\section{INTRODUCTION}

A variety of devices and medications are available to facilitate intubation. ${ }^{1,2}$ Direct laryngoscopy (DL) has been considered the gold standard in airway management, with the Macintosh blade being the most common laryngoscope blade utilized for emergent endotracheal intubation (EETI). ${ }^{3,4}$ Indirect laryngoscopy is a relatively new technology and includes video laryngoscopy (VL) and flexible intubation scopes. ${ }^{4,5} \mathrm{VL}$ offers improved visualization of the laryngeal inlet compared to DL and there is emerging evidence that in certain circumstances it may bring additional value for EETI in critically ill patients. ${ }^{6-9}$ Although it has been suggested by some that $\mathrm{VL}$ is the new standard for EETI, ${ }^{10}$ others have expressed concerns over adoption of these newer technologies. ${ }^{11,12}$

In addition to device choice, consideration of patient physiology and the pharmacology of medications for intubation are essential to planning an EETI strategy. ${ }^{2,13}$ Available sedative and paralytic medications have unique benefits/risks, and there is controversy over the optimal medication to administer. Etomidate is commonly used as an induction agent as part of rapid sequence intubation (RSI) in emergency medicine (EM) due to its reported minimal effects on patient hemodynamics; however, there are concerns regarding associated adrenal suppression. ${ }^{14-17}$ Other agents such as ketamine, fentanyl, midazolam, and propofol are frequently used alone or in combination to facilitate EETI in patients with hemodynamic instability. ${ }^{18}$ Rocuronium and succinylcholine are also commonly administered as muscle relaxants for RSI, and debate continues over which is a superior agent for RSI. ${ }^{19,20}$

Data on the use of devices and medications for EETI is incomplete. More information on these intubation practices is required to better understand how EETIs are performed and to allow for planning of future research studies. The aim of this study was to describe the EETI practices of Canadian EM and ICU physicians treating critically ill patients. Specifically, our objectives were to determine the types of intubation devices, sedatives, and paralytics being used to facilitate EETI.

\section{METHODS}

This study was approved by the Nova Scotia Health Authority Research Ethics Board in Halifax, Nova Scotia. The research team developed a clinical scenariobased survey (available in Supplementary Materials) which was revised and validated for face and content validity through an iterative process among study authors and the Canadian Critical Care Trials Group (CCCTG). The survey involved scenarios of patients with congestive heart failure $(\mathrm{CHF})$, pneumonia, or trauma (Appendix 1) and was designed to identify physician preferences for intubation devices and medications. The electronic survey was constructed using the SelectSurvey instrument (www.selectsurvey.net) and administered in both English and French.

A combined web-based and postal strategy was used to administer the survey to all non-trainee physician members of the Canadian Association of Emergency Physicians (CAEP), the Canadian Critical Care Society (CCCS), and the CCCTG. We combined the membership lists from all three societies and removed any duplicate names, physical addresses, or email addresses. The survey was electronically distributed three times over a 3-month period during 2012/2013. Non-responders to the third electronic survey reminder were mailed a hard copy of the survey along with a pre-stamped envelope to complete and return by post. Controls were in place to ensure physicians did not complete and submit more than one survey. A blinded administrative assistant aided in the coordination of survey distribution and ensured all respondents remained anonymous.

Data was collected on physician specialty, affiliation (academic or community hospital), years in practice, completion of a critical care medicine (CCM) fellowship, and if they currently performed EETI in 
their practice. Physicians were presented questions regarding techniques and medications they would use in each scenario and asked to respond using a 5-point Likert scale ranging from "always" to "never" based on "what they would do if they were managing the scenario in their usual place of work" to allow for possible variation among physician practice, resources, and support. Survey respondents were grouped as EM or ICU physicians. The EM group included the EM specialties (Fellow of the Royal College of Physicians of Canada [FRCPC]), EM (Canadian College of Family Physicians [CCFP]-EM certificate), EM (CCFP or other), and family medicine. The ICU group included intensivists from the specialties of anesthesia, internal medicine, and surgery; in addition, any physician from another specialty who had completed a CCM fellowship was included in the ICU group.

A Microsoft Excel ${ }^{\circledR}$ (Microsoft Corp., Redmond, WA) database was created and populated directly with responses from the electronic survey. One investigator (MB) entered responses from the paper-based survey into the database. The accuracy of data entry from paperbased surveys was confirmed by randomly checking $10 \%$ of the responses. In the analysis, we included any survey question that was fully answered; single and multipart questions that were incompletely answered were excluded. We used descriptive statistics (proportions, means, ranges) and graphically represented the stated practices of physicians as diverging stacked bar charts using a compressed 5-point Likert scale (always/often, sometimes, rarely/never). Multivariable logistic regression was used to model the association between predictor variables of physician characteristics (primary specialty [reference: internal medicine], years of practice [reference: $<1$ year], CCM fellowship [reference: no CCM fellowship]) and dichotomous outcome variables (backup intubation strategy, use of paralytics). Associations identified through the multivariable analyses were expressed as adjusted odds ratios (aORs) and 95\% confidence intervals (CIs). A $p$-value of $<0.05$ was considered to be significant for all statistical tests. All data analysis was performed using R (version 3.1.0, Spring Dance) in the RStudio GUI (version 0.98.932) and IBM SPSS Statistics Version 21. ${ }^{21}$

\section{RESULTS}

The survey was sent to 1,758 physicians with a response rate of $50.2 \%(882 / 1,758)$. Some respondents did not complete all of the survey questions; thus, the denominator for each question varies based on the number of physicians who addressed it. A quality check of $10 \%$ of paper-based survey responses entered in the database revealed $99.8 \%$ accuracy. Characteristics of survey respondents are shown in Table 1 . Of physicians who provided information about their specialty, $73 \%$ (463/634) were grouped as EM physicians and $27 \%(171 / 634)$ as ICU physicians. Most respondents (79\%, 521/661) practiced at an academic hospital, and the majority $(61 \%, 403 / 662)$ had more than 10 years of experience; $26 \%(171 / 657)$ of respondents had a CCM fellowship.

The clinical scenarios included a 67-year-old male with CHF, a 59-year-old female with pneumonia, and a 29-year-old male trauma patient in a cervical spine immobilization collar with abrasions on his head, chest, and abdomen due to a motor vehicle crash (Appendix 1). Physician preferences for primary intubation strategy are shown in Figure 1. Overall, the device most physicians would "always/often" use as their first choice in the three

\begin{tabular}{|c|c|c|c|}
\hline Characteristics & $\begin{array}{c}\text { EM* }^{*} \\
\text { No. }(\%)\end{array}$ & $\begin{array}{c}\mathrm{ICU}^{\dagger}, \\
\text { No. (\%) }\end{array}$ & $\begin{array}{c}\text { All Physicians, } \\
\text { No. (\%) }\end{array}$ \\
\hline \multicolumn{4}{|c|}{$\begin{array}{l}\text { Years in practice } \\
(\mathrm{n}=662)\end{array}$} \\
\hline $11-20$ & $159(34)$ & $55(32)$ & $223(34)$ \\
\hline$>20$ & $117(25)$ & $50(29)$ & $180(27)$ \\
\hline $6-10$ & $97(21)$ & $49(29)$ & 149 (23) \\
\hline $1-5$ & $83(18)$ & $15(9)$ & $101(15)$ \\
\hline$<1$ & $7(2)$ & $2(>1)$ & $9(1)$ \\
\hline \multicolumn{4}{|c|}{ Type of practice $(n=661)$} \\
\hline Academic & 339 (73) & $154(90)$ & $519(78)$ \\
\hline Community & $121(26)$ & $17(10)$ & $140(21)$ \\
\hline Both & $2(>1)$ & $0(0)$ & $2(<1)$ \\
\hline \multicolumn{4}{|l|}{$\begin{array}{l}\text { CCM fellowship } \\
(\mathrm{n}=657)\end{array}$} \\
\hline Yes & $12(3)$ & $140(82)$ & $171(26)$ \\
\hline No & 447 (97) & $30(18)$ & $486(74)$ \\
\hline \multicolumn{4}{|c|}{$\begin{array}{l}\text { Currently performing } \\
\text { EETI }(n=657)\end{array}$} \\
\hline Yes & 459 (99) & $168(98)$ & 651 (99) \\
\hline No & $2(>1)$ & $3(2)$ & $6(1)$ \\
\hline \multicolumn{4}{|c|}{$\begin{array}{l}\text { EM = emergency medicine; ICU = intensive care medicine; } C C M=\text { critical care } \\
\text { medicine; EETI = emergent endotracheal intubation. } \\
\left.{ }^{*} \text { EM physicians included the specialties EM (CCFP-EM) ( } n=275\right) \text {, EM (FRCPC) } \\
(n=126) \text {, EM (CCFP or other) }(n=42) \text {, and family medicine }(n=20) ; \text { percentages are } \\
\text { based on number of EM physicians who answered each question. } \\
{ }^{+} \text {ICU physicians included the specialties internal medicine }(n=96) \text {, anesthesia }(n=57) \text { ), } \\
\text { and surgery }(n=18) \text {; percentages are based on number of ICU physicians who } \\
\text { answered each question. }\end{array}$} \\
\hline
\end{tabular}



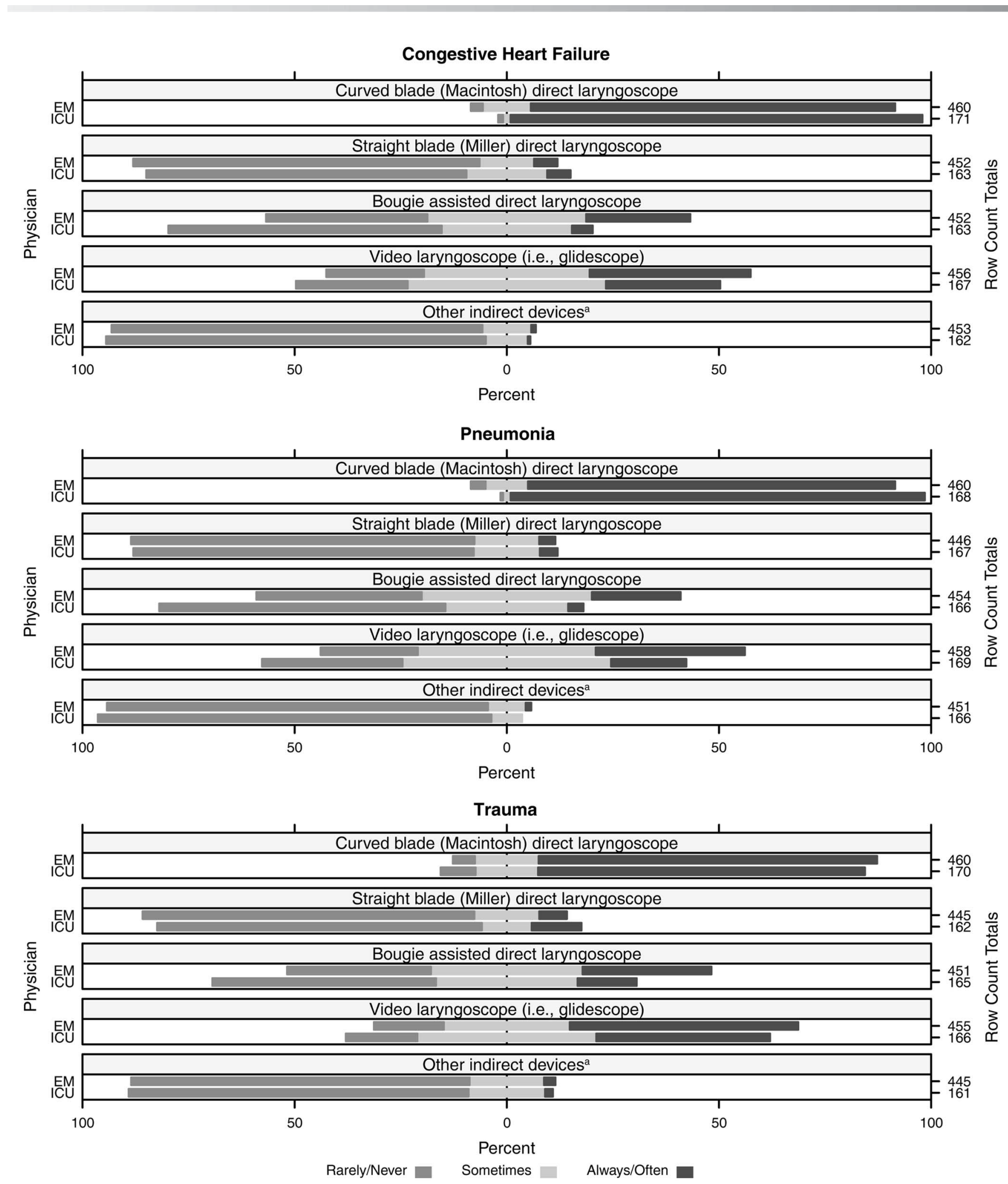

Figure 1. Primary strategy of emergency medicine (EM) and intensive care unit (ICU) physicians for emergent endotracheal intubation in three clinical scenarios. ${ }^{a}$ Other indirect devices include intubating laryngeal mask airway, optical stylet, airtrac, and lightwand. 
scenarios was DL with a Macintosh blade (mean 85.1\% [79.0\%-88.9\%]), followed by VL (mean 37.5\% [29.9\%49.5\%]) and bougie-assisted DL (mean 19.5\% [15.9\%24.9\%]). Most EM physicians would "always/often" use DL with a Macintosh blade in all three scenarios $(\mathrm{CHF}$ $86 \%$, 395/460; pneumonia $87 \%$, 398/460; trauma $80 \%$, 367/460), as would most ICU physicians (CHF 97\%, $166 / 171$; pneumonia $98 \%, 164 / 168$; trauma $77 \%$, $131 / 170)$. In comparison, a smaller proportion of respondents indicated they would "always/often" use VL as their primary intubation strategy in the CHF (EM 38\%, 173/456; ICU 27\%, 45/167), pneumonia (EM 35\%, 161/458; ICU 18\%, 30/169), and trauma (EM 45\%, 245/455; ICU 41\%, 68/166) scenarios. We combined all responses from the three scenarios and examined whether there was an association between physician experience level (i.e., <1 year, 1-5 years, 6-10 years, 11-20 years, $>20$ years) and preference for using DL or VL as a primary intubation strategy. Between these five experience groups, there was little difference in the proportion of physicians who would "always/often" use DL as a primary strategy (range $82 \%-88 \%)$. By comparison, the proportion of physicians who would "always/often" use VL as a primary intubation strategy ranged from $29 \%$ in the $<1$ year group to $52 \%$ in the $1-5$ year group.

Figure 2 shows the devices physicians would use if their primary intubation strategy was unsuccessful. Overall, the device most physicians would "always/ often" use as backup was an extraglottic device (e.g., laryngeal mask airway, laryngeal tube) (mean 58.7\% [56.2\%-60.4\%]), followed by percutaneous cricothyrotomy (mean $4.5 \%$ [4.0\%-5.7\%]). An extraglottic device was most frequently selected "always/often" in all three scenarios by both EM physicians (CHF 63\%, 289/458; pneumonia $61 \%$, 282/461; trauma $59 \%$, 272/458) and ICU physicians (CHF 49\%, 82/167; pneumonia 47\%, 78/166; trauma 48\%, 81/167). EM physicians were more likely than ICU physicians to use an extraglottic device as backup (aOR 2.73; 95\% CI 1.98-3.74).

Physician preferences for medications to facilitate EETI are shown in Figure 3. Overall, most physicians would "always/often" administer fentanyl (mean 45.3\% [42.3\%-50.7\%]), etomidate (mean 38.2\% [24.6\%$50.5 \%]$ ) and propofol (mean 28.3\% [25.7\%-36.1\%]). The medication most EM physicians would "always/ often" use was ketamine in the pneumonia scenario $(61 \%$, 277/457), and etomidate in the CHF (54\%, 246/457) and trauma $(63 \%, 284 / 451)$ scenarios. In contrast, most ICU physicians would "always/often" administer fentanyl in all three scenarios (CHF 77\%, 128/167; pneumonia $76 \%$, 127/168; trauma $75 \%$, 125/166). A greater proportion of ICU physicians indicated they would "always/often" use midazolam (CHF 64\%, 107/166; pneumonia 65\%, 110/168; trauma 59\%, 98/166) compared to EM physicians (CHF 18\%, 84/452; pneumonia $17 \%, 77 / 447$; trauma $16 \%, 71 / 453$ ).

Figure 4 shows physician preferences for use of paralytics to facilitate EETI. Succinylcholine was the drug most EM physicians would "always/often" use for paralysis (CHF 72\%, 329/459; pneumonia 77\%, 356/ 461; trauma 78\%, 358/459). A considerably smaller proportion of ICU physicians would "always/often" use succinylcholine (CHF 18\%, 30/166; pneumonia 19\%, $31 / 166$; trauma 29\%, 49/167). Rocuronium was marginally preferred over succinylcholine for paralysis by ICU physicians in all three scenarios (CHF 27\%, 45/165; pneumonia 30\%, 50/164; trauma 33\%, 54/165). EM physicians chose to paralyze patients more often than ICU physicians (aOR 3.40; 95\% CI 2.90-4.00).

\section{DISCUSSION}

The results of this clinical scenario-based survey demonstrated that a wide variety of practice patterns exist in Canada for EETI in critically ill patients. Most Canadian EM and ICU physicians would use DL with a Macintosh blade as their first choice of device if a similar patient presented in their practice, followed by VL. If their first choice was unsuccessful, most physicians would use an extraglottic device as a backup strategy. The sedatives most physicians would use to facilitate EETI were fentanyl and etomidate; however, there was variation between EM and ICU physicians in their preferences of which sedatives to use in each of the three clinical scenarios. Overall, EM physicians were considerably more likely than ICU physicians to use paralytics for EETI. Choice of paralytic agent varied, with EM physicians preferring succinylcholine for paralysis while ICU physicians preferred rocuronium. These findings provide evidence of variation between the intubation practices of Canadian EM and ICU physicians and reinforce the need for further investigation into the optimal approaches to EETI in critically ill patients.

Unlike intubations in the operating room where the primary objective is induction of anesthesia, EETIs are 

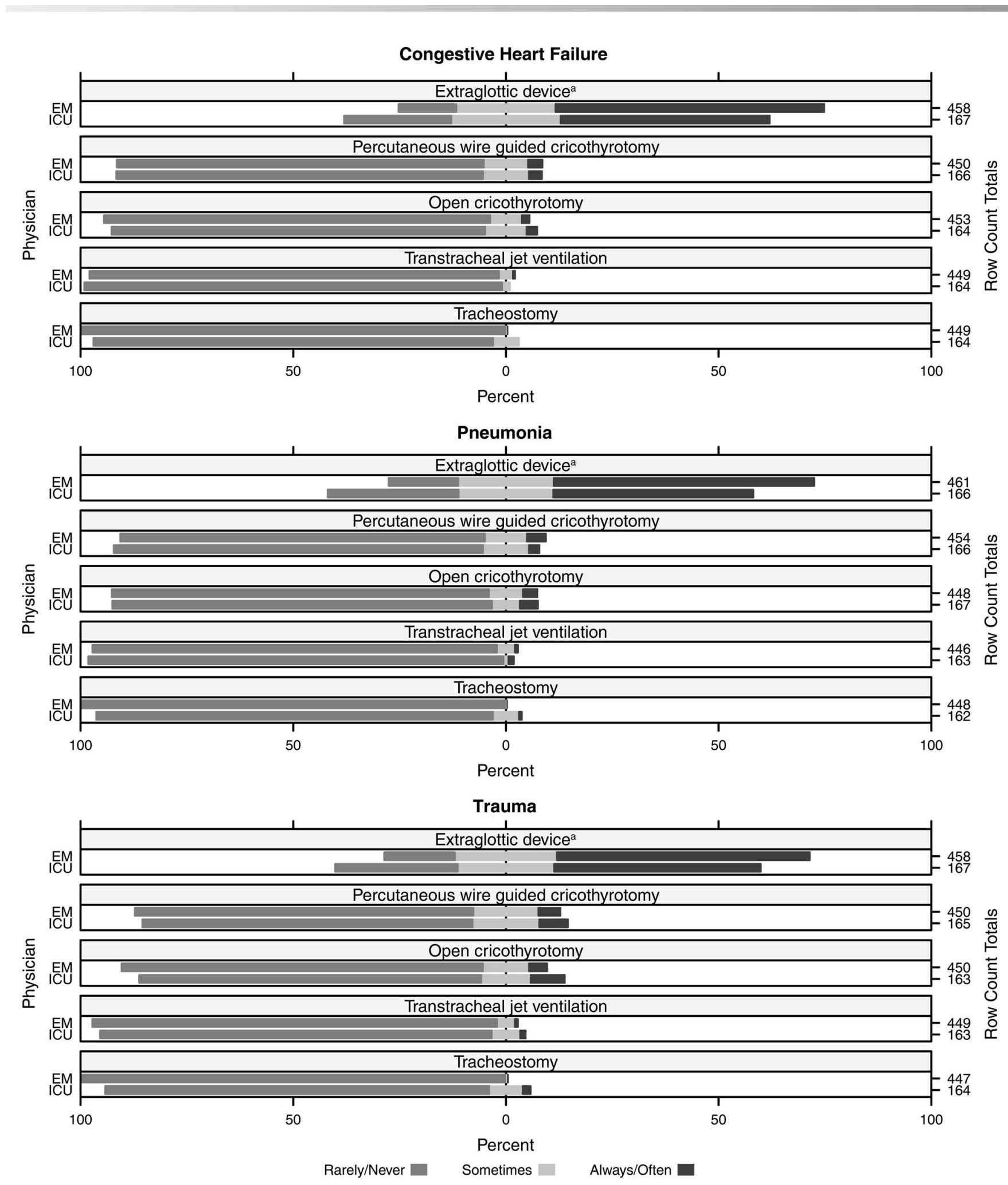

Figure 2. Backup strategy of emergency medicine (EM) and intensive care unit (ICU) physicians for emergent endotracheal intubation if their primary strategy was unsuccessful. ${ }^{a}$ Extraglottic devices include LMA, King LT, etc.

often performed in unstable patients with the goal of securing the airway as a life-saving intervention in a patient with respiratory failure or shock. ${ }^{1,2}$
The procedure is associated with life-threatening adverse events due to multiple factors related to the patient (comorbidities, limited cardiopulmonary 

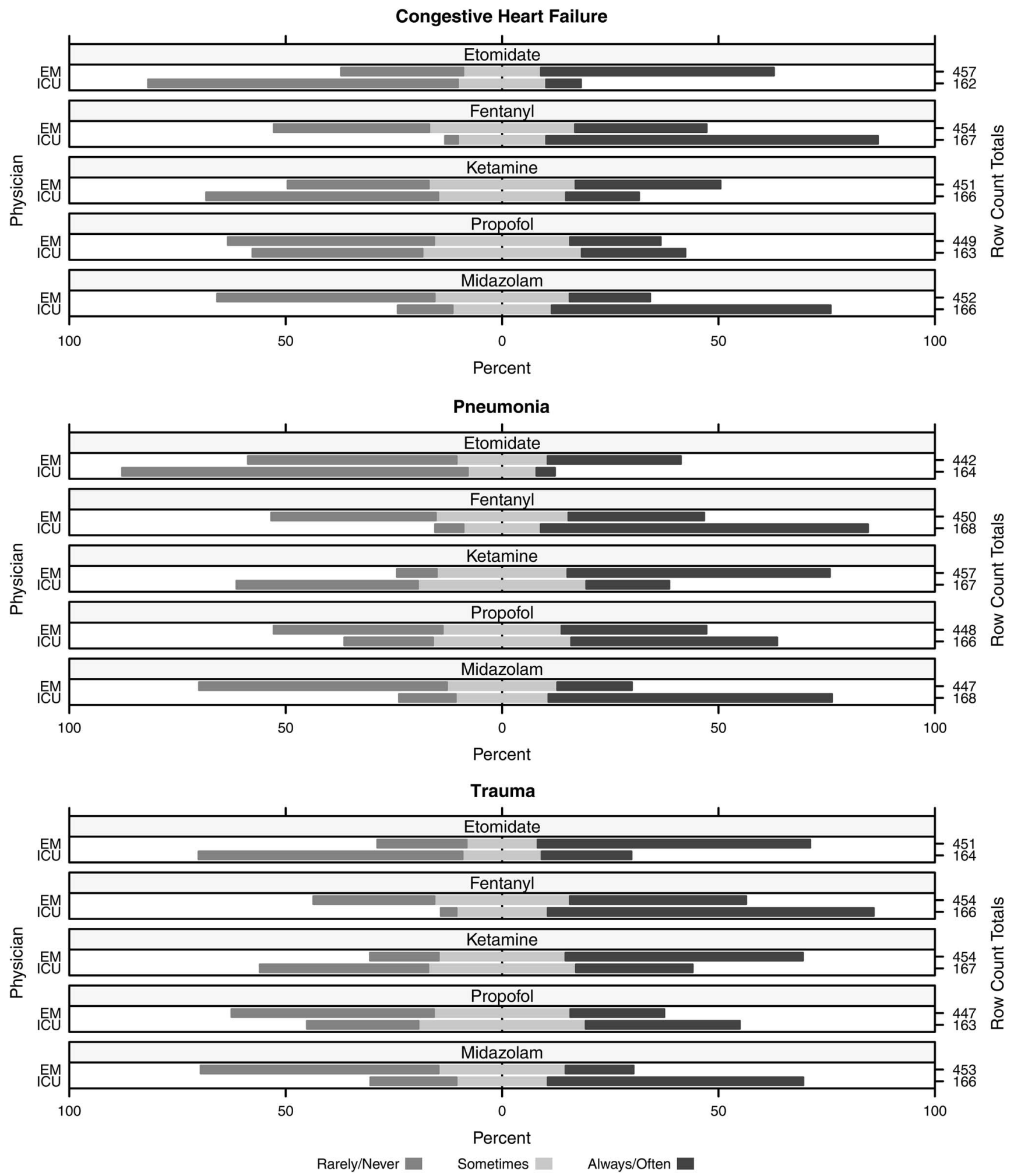

Figure 3. Sedatives and anesthetic choices of emergency medicine (EM) and intensive care unit (ICU) physicians to facilitate emergent endotracheal intubation. 

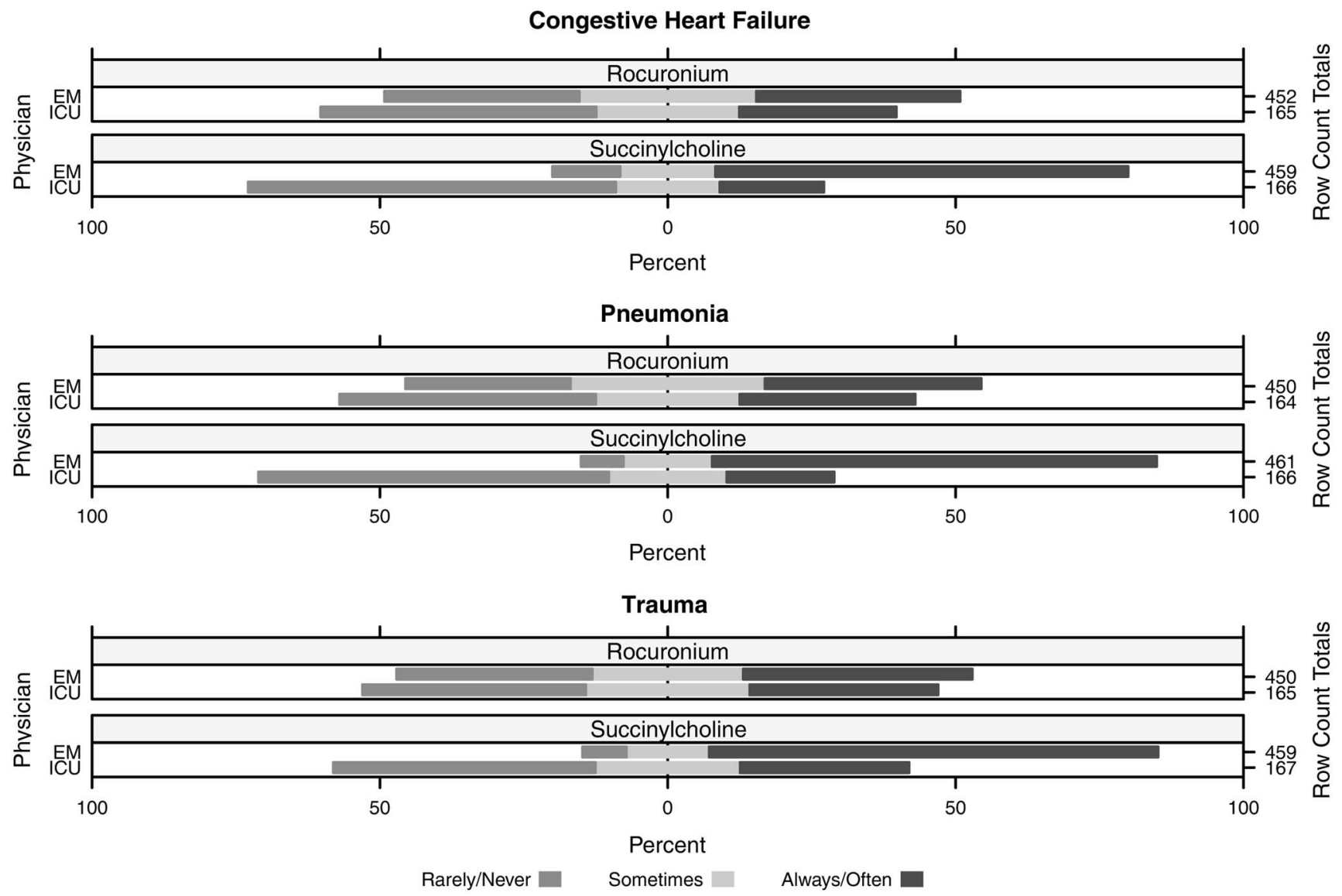

Figure 4. Paralytic preferences of emergency medicine (EM) and intensive care unit (ICU) physicians to facilitate emergent endotracheal intubation.

reserve, etc.), staff (training level of intubator, skill level and experience of nurses), and environment (limited range of airway equipment, crowded bedside). ${ }^{1,22-24}$ Device and drug choices to facilitate EETI can significantly impact the outcomes of the procedure. ${ }^{2,13,25}$ While there has been controversy in EM and ICU circles over the pharmacology and approach to EETI, little data is available on actual clinical practice. ${ }^{23,25-31}$

When comparing intubation devices, it is important to consider the heterogeneity in design of newer technologies being used as alternatives to DL, the availability of intubation equipment, and the training level of the intubator. ${ }^{11}$ Our finding that most Canadian physicians perform EETI using DL with a Macintosh blade is similar to the results of recent observational studies. In a prospective single-center study of EETI practices in Australia, Phillips and colleagues found EETI was performed most commonly using DL with a Macintosh blade (50\% of intubations) followed closely by use of C-MAC VL (45.5\% of intubations). ${ }^{26}$ An earlier prospective single-center study of Australian EETI practices also found intubation was performed most commonly using DL with a Macintosh blade (53.5\% of intubations) followed by use of C-MAC VL (45.9\% of intubations). ${ }^{27}$ In a multicenter prospective surveillance study of 17,583 adult emergency intubations in the United States, Canada, and Australia between 2002 and 2012, Brown and colleagues examined 13 centers and found DL was used in $84 \%$ of first attempts while use of $\mathrm{VL}$ increased from under $1 \%$ in the first three years to $27 \%$ in the last three years of the study. ${ }^{25}$ Another prospective multicenter study of EETI practices in Japan found the vast majority of intubations (90.5\%) were performed using DL, followed by use of $\mathrm{VL}$ in $4.1 \%$ of cases. ${ }^{28}$ In addition, there have been two Canadian surveys of the practices of anesthesiologists in difficult airway scenarios. Both surveys found DL to be the preferred intubation technique, ${ }^{29,30}$ and that most anesthetists would use VL in an unanticipated difficult intubation situation if DL was unsuccessful. ${ }^{30}$ 
Several studies comparing rates of first pass success and complications between DL and VL in emergency intubations suggest VL may offer advantages for novice intubators and nonanesthesiologists, or in difficult airway situations; however, these improved success rates in comparative studies have not demonstrated a significant difference in complication rates with the exception of one study which found reduced rates of esophageal intubation and oxygen desaturation events with VL, ${ }^{32}$ and the reported first pass success rates are not superior to historical benchmarks from large sets of registry data. ${ }^{6-8,32-36}$ A systematic review and metaanalysis of DL and VL use in ICU patients included 9 trials (2,133 patients) and found that VL reduced the risk of difficult orotracheal intubation (OR 0.29; 95\% CI 0.20-0.44), Cormack 3/4 grades (OR 0.26; 95\% CI $0.17-0.41$ ), and esophageal intubation (OR 0.14; 95\% CI 0.02-0.81), and increased first-attempt success (OR 2.07; 95\% CI 1.35-3.16) compared to DL. ${ }^{37}$ In contrast, a systematic review and meta-analysis of DL and VL use in the emergency room or prehospital setting included four trials (1,305 patients) and found no benefit to use of VL over DL with respect to intubation success, time to intubation, and the glottic view achieved by the device. ${ }^{38}$ Recently, two randomized controlled trials (RCTs) have compared use of DL and $\mathrm{VL}$ in the emergency department (ED). In one trial, 198 patients undergoing EETI were randomly assigned to either DL or VL using a C-MAC device for the initial intubation attempt; the study authors did not detect a difference between VL or DL using the C-MAC device in first-pass success, attempt duration, aspiration pneumonia, or hospital length of stay. ${ }^{39}$ A second RCT randomized 140 patients requiring EETI during cardiopulmonary resuscitation to either DL or VL by an experienced intubator; there were no differences in first-pass success, EETI success rate, or time to complete EETI between the DL and VL groups, but VL was better for completing EETI without chest compression interruptions. ${ }^{40}$ Despite a call from some authors for the exclusive use of VL for EETI, ${ }^{10}$ our study demonstrates that DL is still the primary choice of physicians practicing EETI in Canada.

Similar to our findings, previous studies have reported variability in the sedative medications used for emergency intubation. One prospective observational study from Australia reported thiopentone was used most often $(72.9 \%)$ for EETI in the ED, followed by use of ketamine (8.5\%). ${ }^{27}$ Another study of Australian
ED and ICU resuscitation practices found most adult intubations were facilitated with fentanyl (67\%), followed by propofol (61.6\%). ${ }^{26} \mathrm{~A}$ survey of Italian ED intubation practices found the sedatives used most often were midazolam $(59.7 \%)$ and propofol $(46.3 \%) .{ }^{41} \mathrm{In}$ their study of 13 EDs (11 in the United States, 1 in Canada, 1 in Australia), Brown and colleagues found the medication used most often for adult intubation was etomidate $(91 \%)$, followed by midazolam $(3.2 \%){ }^{25}$ Since the majority of ED intubations in this multicenter study were performed in the United States (96\%, $16,910 / 17,583)$, these findings suggest that etomidate is widely used for EETI in the United States. Although our study found most Canadian physicians would use fentanyl to facilitate EETI overall, we also observed that most EM physicians would administer etomidate in the CHF (54\%) and trauma (63\%) scenarios.

Our finding that most Canadian physicians prefer succinylcholine for paralysis in EETI is in accordance with other studies. An Australian observational study of EETI found succinylcholine was used in $86.8 \%$ of ED intubations, ${ }^{27}$ while a second study reported that succinylcholine was used in $85.7 \%$ of ED and ICU intubations. ${ }^{26}$ A study of modified RSI practice in the United States surveyed all anesthesia residency training programs and found most residents and physicians preferred succinylcholine (58\%) followed by rocuronium $(39 \%)$ during RSI procedures. ${ }^{42}$ Finally, Brown and colleagues found $75 \%$ of the adult emergency intubations in their prospective multicenter study were performed using succinylcholine as a paralytic. $^{25}$ Collectively, these results suggest succinylcholine is the medication used most widely by physicians for paralysis in critically ill patients. However, our finding that rocuronium was marginally preferred over succinylcholine by ICU physicians in Canada provides evidence of variation in EETI practice between specialties. While we are unable to determine from this study why EM physicians were more likely than ICU physicians to use paralytics, we believe this highlights a practice variation that warrants further investigation.

The use of devices and medications are certainly not the only factors that can affect intubation success. A number of algorithms and guidelines have been proposed to reduce variation in the practice of EETI and decrease the incidence of adverse events. These include the Eastern Association for the Surgery of Trauma Practice Management Guidelines for emergency tracheal intubation, ${ }^{43}$ the Montpellier-ICU intubation algorithm, ${ }^{44}$ 
and recommendations for difficult airway management from the Canadian Airway Focus Group. ${ }^{45,46}$ While there is some evidence that an intubation management protocol can reduce EETI-related adverse events when compared to a conventional strategy, ${ }^{47}$ it is unknown how widely such protocols have been implemented in clinical practice. Simulation-based training has been reported to improve intubation success rates in some studies, ${ }^{48}$ but not others. ${ }^{49}$ Additional methods found to improve intubation success include the use of preprocedural checklists ${ }^{50}$ and preoxygenation. ${ }^{51}$

As with all surveys, this study has limitations. The $49.8 \%$ survey non-response rate is an important limitation of this study, since the practices of these nonresponding physicians may impact the validity of our findings. Most physicians who responded to the survey practiced in academic settings; this may bias the results and limit their generalizability to Canadian physicians, especially those practicing in non-academic settings. Another possible source of bias is the method used to identify study participants. We used the mailing lists of CAEP, the CCCS, and the CCCTG to identify practicing EM and ICU physicians. These organizations do not represent all EM and ICU physicians in Canada; however, these mailing lists were the most comprehensive national listings of EM and ICU physicians that were available to the study team. It is also important to note that we did not specifically ask physicians about their training, access, or familiarity with VL. Furthermore, since physicians self-reported on their resuscitation practices, some discrepancy may exist between their self-reported preferences and the actual frequencies of device/drug use that would be measured if their practice was observed. We attempted to minimize this by instructing physicians to answer survey questions based on what they would do if they were managing a patient in their usual place of work.

Despite these limitations, we believe this national survey of resuscitation practices among EM and ICU physicians provides valuable insight into the devices and drugs currently being used to perform EETI in Canada, including preferences for a backup intubation strategy. The main strengths of this study are that the clinical scenarios and survey questions were developed and refined by experts in EETI and members of the CCCTG using a rigorous methodology based on guidelines for surveying clinicians from the Academy of Critical Care: Development, Evaluation, and Methodology (ACCADEMY) Group, ${ }^{52}$ and that the survey was administered in both electronic and paper-based versions to all members (French and English) of three national societies. This study of Canadian physicians demonstrates that while there is consensus in some aspects of EETI practice such as device preference, there is considerable variability in other aspects such as which medications to use. The findings of this survey provide information that will aid in the planning of future investigations.

\section{CONCLUSION}

The results of this survey highlight the practice patterns in Canada for intubation in critically ill patients. Despite the availability of novel video devices, most EM and ICU physicians chose DL with a Macintosh blade for EETI. Medications used to facilitate intubation, including the use of paralytics, was variable. Additional work is required to determine the optimal approaches to performing EETI in the critically ill population.

Acknowledgements: The authors thank Kristen Griffiths, Hilary Van Loon, and Mari Ito for assisting with survey distribution and Dr. Patrick Archambault for critical review of the manuscript.

Competing Interest: This study was funded by a Clinician Scientist Award from the Dalhousie University Faculty of Medicine, and a grant from the Capital Health Research Fund, Halifax, NS. The authors declare they have no other financial or other conflicts of interests related to this submission.

\section{SUPPLEMENTARY MATERIAL}

To view supplementary material for this article, please visit http://dx.doi.org/doi:10.1017/cem.2016.361

\section{REFERENCES}

1. Simpson GD, Ross MJ, McKeown DW, et al. Tracheal intubation in the critically ill: a multi-centre national study of practice and complications. Br 7 Anaesth 2012;108(5): 792-9.

2. Mechlin MW, Hurford WE. Emergency tracheal intubation: techniques and outcomes. Respir Care 2014;59(6):881-94.

3. Burkle CM, Zepeda FA, Bacon DR. A historical perspective on use of the laryngoscope as a tool in anesthesiology. Anesthesiology 2004;100(4):1003-6.

4. Collins SR. Direct and indirect laryngoscopy: equipment and techniques. Respir Care 2014;59(6):850-64.

5. Niforopoulou P, Pantazopoulos I, Demestiha T, et al. Video-laryngoscopes in the adult airway management: a topical review of the literature. Acta Anaesthesiol Scand 2010;54(9):1050-61. 
6. Silverberg MJ, Li N, Acquah SO, et al. Comparison of video laryngoscopy versus direct laryngoscopy during urgent endotracheal intubation: a randomized controlled trial. Crit Care Med 2015;43(3):636-41.

7. Michailidou M, O'Keeffe T, Mosier JM, et al. A comparison of video laryngoscopy to direct laryngoscopy for the emergency intubation of trauma patients. World $7 \mathrm{Surg}$ 2015;39(3):782-8.

8. Su YC, Chen CC, Lee YK, et al. Comparison of video laryngoscopes with direct laryngoscopy for tracheal intubation: a meta-analysis of randomised trials. Eur 7 Anaesthesiol 2011;28(11):788-95.

9. Sakles JC, Javedani PP, Chase E, et al. The use of a video laryngoscope by emergency medicine residents is associated with a reduction in esophageal intubations in the emergency department. Acad Emerg Med 2015;22(6):700-7.

10. Zaouter C, Calderon J, Hemmerling TM. Videolaryngoscopy as a new standard of care. Br $\mathcal{F}$ Anaesth 2015; 114(2):181-3.

11. Kovacs G. Airway management: "the times they are a-changin." CFEM 2013;15(6):317-20.

12. Bulatovic R, Taneja R. Videolaryngoscopy - for all intubations? Br $\mathcal{F}$ Anaesth 2015;115(1):135-6.

13. Consilvio C, Kuschner WG, Lighthall GK. The pharmacology of airway management in critical care. $\mathcal{F}$ Intensive Care Med 2012;27(5):298-305.

14. Bruder EA, Ball IM, Ridi S, et al. Single induction dose of etomidate versus other induction agents for endotracheal intubation in critically ill patients. Cochrane Database Syst Rev 2015;1:CD010225.

15. Vinclair M, Broux C, Faure $P$, et al. Duration of adrenal inhibition following a single dose of etomidate in critically ill patients. Intensive Care Med 2008;34(4): 714-9.

16. Bloomfield R, Noble DW. Etomidate and fatal outcomeeven a single bolus dose may be detrimental for some patients. Br $\mathcal{F}$ Anaesth 2006;97(1):116-7.

17. Archambault P, Dionne CE, Lortie G, et al. Adrenal inhibition following a single dose of etomidate in intubated traumatic brain injury victims. CFEM 2012;14(5): 270-82.

18. Abbasivash R, Aghdashi MM, Sinaei B, et al. The effects of propofol-midazolam-ketamine co-induction on hemodynamic changes and catecholamine response. 7 Clin Anesth 2014;26(8):628-33.

19. Girard T. Pro: rocuronium should replace succinylcholine for rapid sequence induction. Eur $\mathcal{F}$ Anaesthesiol 2013; 30(10):585-9.

20. Schreiber JU. Con: succinylcholine should not be replaced by rocuronium for rapid sequence induction. Eur 7 Anaesthesiol 2013;30(10):590-3.

21. IBM Corp. IBM SPSS Statistics for Windows, Version 21.0. Armonk: IBM Corp.; 2012.

22. Griesdale DEG, Bosma TL, Kurth T, et al. Complications of endotracheal intubation in the critically ill. Intensive Care Med 2008;34(10):1835-42.

23. Jaber S, Amraoui J, Lefrant JY, et al. Clinical practice and risk factors for immediate complications of endotracheal intubation in the intensive care unit: a prospective, multi-center study. Crit Care Med 2006;34(9): 2355-61.

24. Zamora JE, Weber BJ, Langley AR, et al. Laryngoscope manipulation by experienced versus novice laryngoscopists. Can $\mathcal{F}$ Anaesth 2014;61(12):1075-83.

25. Brown CA 3rd, Bair AE, Pallin DJ, et al. NEAR III Investigators. Techniques, success, and adverse events of emergency department adult intubations. Ann Emerg Med 2015;65(4):363-70.

26. Phillips L, Orford N, Ragg M. Prospective observational study of emergent endotracheal intubation practice in the intensive care unit and emergency department of an Australian regional tertiary hospital. Emerg Med Australas 2014;26(4):368-75.

27. Fogg T, Annesley N, Hitos K, et al. Prospective observational study of the practice of endotracheal intubation in the emergency department of a tertiary hospital in Sydney, Australia. Emerg Med Australas 2012;24(6): 617-24.

28. Nakao S, Kimura A, Hagiwara Y, et al. Japanese Emergency Medicine Network Investigators. Trauma airway management in emergency departments: a multicentre, prospective, observational study in Japan. BM7 Open 2015; 5(2): 0006623.

29. Jenkins K, Wong DT, Correa R. Management choices for the difficult airway by anesthesiologists in Canada. Can 7 Anaestb 2002;49(8):850-6.

30. Wong DT, Mehta A, Tam AD, et al. A survey of Canadian anesthesiologists' preferences in difficult intubation and "cannot intubate, cannot ventilate" situations. Can 7 Anaesth 2014;61(8):717-26.

31. Lapinsky SE. Endotracheal intubation in the ICU. Crit Care 2015;19:258.

32. Hypes CD, Stolz U, Sakles JC, et al. Video laryngoscopy improves odds of first-attempt success at intubation in the intensive care unit. A propensity-matched analysis. Ann Am Thorac Soc 2016;13(3):382-90.

33. Vassiliadis J, Tzannes A, Hitos K, et al. Comparison of the C-MAC video laryngoscope with direct Macintosh laryngoscopy in the emergency department. Emerg Med Australas 2015;27(2):119-25.

34. Silverberg MJ, Li N, Acquah SO, et al. Comparison of video laryngoscopy versus direct laryngoscopy during urgent endotracheal intubation: a randomized controlled trial. Crit Care Med 2015;43(3):636-41.

35. Brown CA 3rd, Pallin DJ, Walls RM. Video laryngoscopy and intubation safety: the view is becoming clear. Crit Care Med 2015;43(3):717-8.

36. Choi HJ, Kim YM, Oh YM, et al. GlideScope video laryngoscopy versus direct laryngoscopy in the emergency department: a propensity score-matched analysis. $B M \mathcal{J} O$ pen 2015;5(5):e007884.

37. De Jong A, Molinari N, Conseil M, et al. Video laryngoscopy versus direct laryngoscopy for orotracheal intubation in the intensive care unit: a systematic review and metaanalysis. Intensive Care Med 2014;40(5):629-39.

38. Lee $\mathrm{Y}$, Chen $\mathrm{C}, \mathrm{T}$ Wang, et al. Comparison of video and direct laryngoscope for tracheal intubation in emergency settings: a meta-analysis. 7 Acute Med 2012; 2(2):43-9. 
39. Driver BE, Prekker ME, Moore JC, et al. Direct versus video laryngoscopy using the C-MAC for tracheal intubation in the emergency department, a randomized controlled trial. Acad Emerg Med 2016;23(4):433-9.

40. Kim JW, Park SO, Lee KR, et al. Video laryngoscopy vs. direct laryngoscopy: Which should be chosen for endotracheal intubation during cardiopulmonary resuscitation? A prospective randomized controlled study of experienced intubators. Resuscitation 2016;105:196-202.

41. Sanchez LD, Di Martino P, Babineau M, et al. Intubation practice patterns in Tuscan emergency departments. Int $\mathcal{Z}$ Emerg Med 2008;1(2):127-9.

42. Ehrenfeld JM, Cassedy EA, Forbes VE, et al. Modified rapid sequence induction and intubation: a survey of United States current practice. Anesth Analg 2012;115(1):95-101.

43. Mayglothling J, Duane TM, Gibbs M, et al. Eastern Association for the Surgery of Trauma. Emergency tracheal intubation immediately following traumatic injury: an Eastern Association for the Surgery of Trauma practice management guideline. 7 Trauma Acute Care Surg 2012; 73(5 Suppl 4):S333-40.

44. De Jong A, Jung B, Jaber S. Intubation in the ICU: we could improve our practice. Crit Care 2014;18(2):209.

45. Jaber S, Jung B, Corne $\mathrm{P}$, et al. An intervention to decrease complications related to endotracheal intubation in the intensive care unit: A prospective, multiple-center study. Intensive Care Med 2010;36(2):248-55.

46. Law JA, Broemling N, Cooper RM, et al. The difficult airway with recommendations for management - part 1 difficult tracheal intubation encountered in an unconscious/ induced patient. Can 7 Anaestb 2013;60(11):1089-18.

47. Law JA, Broemling N, Cooper RM, et al. The difficult airway with recommendations for management - part 2 - the anticipated difficult airway. Can $\mathcal{F}$ Anaesth 2013;60(11):1119-38.

48. Mosier JM, Malo J, Sakles JC, et al. The impact of a comprehensive airway management training program for pulmonary and critical care medicine fellows. A three-year experience. Ann Am Thorac Soc 2015;12(4):539-48.

49. Lubin J, Carter R. The feasibility of daily mannequin practice to improve intubation success. Air Med 7 2009;28(4):195-7.

50. Smith KA, High K, Collins SP, et al. A preprocedural checklist improves the safety of emergency department intubation of trauma patients. Acad Emerg Med 2015;22(8):989-2.

51. Mort TC. Preoxygenation in critically ill patients requiring emergency tracheal intubation. Crit Care Med 2005;33(11): 2672-5.

52. Burns KEA, Duffett $M$, Kho ME, et al. A guide for the design and conduct of self-administered surveys of clinicians. CMA7 2008;179(3):245-52.

\section{APPENDIX 1}

The three clinical scenarios (congestive heart failure, pneumonia, trauma) that were included in the survey are as follows:

\section{Congestive beart failure scenario}

You are asked to see a 67-year-old male with $\mathrm{CHF}$ and respiratory distress. His past history included ischemic heart disease (3 previous myocardial infarcts, most recent 8 month ago, PTCA twice), hypertension, hypercholesterolemia, and mild renal insufficiency (baseline Cr 140). His vital signs are HR 120, RR 32, $\mathrm{BP} 100 / 56, \mathrm{SaO}_{2} 90 \%$ (on $\mathrm{FiO}_{2} 100 \%$ ), and temperature $36.8^{\circ} \mathrm{C}$. You feel that he requires immediate intubation. He has no predictors of a difficult airway other than moderate obesity (weight $140 \mathrm{~kg}$ ).

\section{Pneumonia scenario}

You are asked to see a 59-year-old female with pneumonia and respiratory distress. Her past history includes hypertension and hypercholesterolemia. Her vital signs are $\mathrm{HR} 120$, RR 32, BP 100/56, $\mathrm{SaO}_{2} 90 \%$ (on $\mathrm{FiO}_{2} 100 \%$ ), and temperature $38.9^{\circ} \mathrm{C}$. You feel that she requires immediate intubation. She has no predictors of a difficult airway. Her weight is $70 \mathrm{~kg}$.

\section{Trauma scenario}

You are asked to see a 29-year-old male involved in a motor vehicle crash. He was a belted passenger of a single vehicle crash in which the driver was killed. He has abrasions on his head, chest and abdomen. He has a chest tube on his left hemithorax for a "flail chest", and remains in a cervical spine immobilization collar and a backboard. He was previously healthy and his weight is $90 \mathrm{~kg}$. His vital signs are HR 120, RR 32, BP 100/56, $\mathrm{SaO}_{2} 90 \%$ (on $\mathrm{FiO}_{2} 100 \%$ ), and temperature $36.8^{\circ} \mathrm{C}$. His GCS is 6. You agree that he requires immediate intubation. He has no predictors of a difficult airway other then cervical immobilization. 